Ankara Ecz. Far, Mec.

7. 120 (1977)
J, Fac. Pharm Ankara

7. 120 (1977)

\title{
Orthurus Heterocarpus (Boiss.) Juz. Bitkisinin Kökleri Üzerinde Farmakognozik Araştırmalar*
}

Pharmacognosic Researches On The Roots of Orthurus heterocarpus (Boiss.) Juz.

\section{Mekin TANKER}

\section{Bilge ŞENER**}

Orthurus heterocarpus (Boiss.) Juz., (Rosaceae) memleketimizin güney Anadolu bölgesinde yaygın olarak rastlanılan ve kökleri halk arasında stomaşik ve antidiyareik amaçlarla kullanılan çok yıllık, rizomlu bir bitkidir. Bitkinin morfolojik, kök ve rizomların anatomik özellikleri daha önceki çalışmamızda (14) belirtildiğinden burada bitkinin toprakaltı kısmlarının kimyasal yapısı ortaya konulmuştur.

\section{DENEL K IS I M}

\section{A T E R Y A L}

Antalya'nın Elmalı ilçesine bağlı bulunan Çığlıkara yöresinde, 1790-2300 m yükseklerde, sedir ağaçlarının altında, kayalar arasında tek ya da kümeler halinde bulunan O.heterocarpus bitkisi 1975 mayıs, ağustos ve 1976 mayıs aylarında toplandı.

Üzerinde kimyasal çalışmalarımızı yürüteceğimiz kök ve rizomlar, topraküstü kısımlarından ayrıldıktan sonra, gölgede kurutuldu ve değirmende kaba toz haline getirildi. Karşılaştırma yapmak üzere, Ankara-Beynam ormanindan toplanan Geum urbanum bitkisinin de topraküstü kısımları ayrıldıktan sonra kök ve rizomları gölgede kurutularak, kaba toz haline getirildi.

Redaksiyona verildiği tarih: 20.10.1977

* Ecz. Bilge Şener'in aynı isimli Doktora Tezinin Kimyasal kismınn özetidir. Sinav tarihi : Şubat 1977. TBTAK VI. Bilim kongresinde tebliğ edilmiştir.

Úniversitesi.

** Farmakognozi ve Farmasötik Botanik Kürsüsü, Eczacılık Fakültesı, Ankara 
Y Ö N T M

Toprakaltı kısımlarının kimyasal yapısının araştırılmasına geçilmeden önce, klâsik yöntemlerle taze materyalde su, gölgede kurutulmuş kök ve rizomlardaki rutubet ve kül miktarları tayin edildi.

Sonra birtakım kimyasal tepkimelerle bu organların içerdikleri etken maddelerin neler oldukları saptanarak, belirlenen maddelerin miktarları tayin edildi.

Alınan enine kesilerin Sudan III ile verdikleri ve $70^{\circ}$ lik etanolde eriyen turuncu renkli yağ damlalarından kök ve rizomlarda uçucu yă̆ bulunduğu anlaşılmıştır. Uçucu yağın miktarı, GLEVENGER apareyinde volümetrik olarak ve ayrıca gravimetrik yöntemle tayin edilmiştir.

Kök ve rizomların etanollü çözeltisinde ferri klorür ile siyahımsı mavi rengin oluşumu tanenin varlığını gösterirken, DRAGENDORFF belirteci ile herhangi bir değişikliğin olmaması alkaloit bulunmadığını ortaya koymuştur. Fehling belirteci ile, hidrolizden önce ve sonra yapılan denemelerde, kırmızı renkli $\mathrm{Cu}_{2} \mathrm{O}$ 'in çökmesi oz ve ozitlerin bulunduğunu göstermiştir. Oz ve holozitler inen usul kâğıt kromatografisi ile, SCHLEISCHER-SGHÜLL 2043a kâğıdı ve n-butanol: piridin: su $(9: 5: 4)$ solvan sistemi ve $\beta$-naftilamin revelatörü kullanılarak teşhis edilmiştir. Miktar tayinleri ise hidrolizden önce ve sonra BERTRAND yöntemi ile yapılmıştır.

Kök ve rizomlarda bulunan bu maddelerden uçucu yağ ve tanen izole edilerek, özelikleri saptandı vé miktarları tayin edildi. Subuharı distilasyonu ile elde edilen uçucu yağın fiziksel ve kimyasal özellikleri saptanarak, bileşimi ince tabaka kromatografisi (8) ve daha duyarlı olan gaz-sıvı kromatografisi yardımıyla belirlenmiştir. Uçucu yağın analizi için gaz kromatografta değişik stasyoner fazlar taşıyan değişik kolonlar ve çeşitli koşullar denenmiştir. Uçucu yağın bileşiminde bulunan maddelerin kesinlikle ayrilabilmesi ve kantlanmasi için başlıa beş sistemden yararlanılmıştır. Bunlar,

Sistem I : $170^{\circ} \mathrm{C}$, cam kolon $(0.55 \times 200 \mathrm{~cm})$, Carbowax $20 \mathrm{M}$,

Sistem II : $140^{\circ} \mathrm{C}$, bakır kolon $(0.15 \times 800 \mathrm{~cm})$, Silicon SF-96,

Sistem III : $50^{\circ} \mathrm{C}$, bakır kolon $(0.15 \times 800 \mathrm{~cm}), \beta, \beta^{\prime}$-oksidipropionitril,

Sistem IV $60^{\circ} \mathrm{C}$, bakir kolon $(0.15 \times 800 \mathrm{~cm})$, PEG 20M,

Sistem V : $160^{\circ} \mathrm{C}$, bakır kolon $(0.15 \times 800 \mathrm{~cm})$, PEG $20 \mathrm{M}$ olan sistemlerdir. 
Kromatogramlarda her maddeye ait pik alanlarının Planimetre yardımıyla ölçülmesinden yararlanarak, bu maddelerin miktarları tayin edilmiştir. Diğer taraftan, alkali ekstraksiyon (4), bromür-bromat (11) ve VAN URK (15) yöntemleri ile uçucu yağda, fenolik maddelerin miktar tayini yapılmıştır. Uçucu yağdan alkali ile ekstraksiyon (2) ve kolon kromatografisi yardımıyla öjenol elde edilmiş ve özellikleri saptanmıștır.

Değiş̧irilmiş deri tozu yöntemi (13) ile kök ve rizomlarda bulunan toplam tanen miktarı saptandıktan başka, elde edilen tanenden gallik asit (9) izole edilerek özelikleri belirtilmiştir.

B ULGULAR

O.hoterocarpus bitkisinin toprakaltı kısımlarında bulunan su, kurutulmuş materyaldeki rutubet ve kül miktarları Tablo I de verilmiştir.

Tablo I. O. heterocarpus'un kök ve rizomlarındaki su, rutubet ve kül miktarları.

\begin{tabular}{|l|c|c|c|}
\hline & Su (\%) & Rutubet (\%) & Kül (\%) \\
\hline Giç̧ekli iken toplanan & 56.0 & 11.8 & 1.46 \\
Meyvalı " $"$ & 42.0 & 8.6 & 1.30 \\
\hline
\end{tabular}

İnen usul kâğıt kromatografisi ile etanollü ekstrede glukoz, fruktoz ve sakaroz saptanmıştır. Invertaz ve emülsin hidrolizleri sonunda sadece glukoz ve fruktoz bulunmuştur. Yapilan asit hidroliz heterozitleri de parçaladığından, glukoz ve fruktoza ek olarak, kromatogramda arabinoz da görülmektedir (Krom. 1).

Kök ve rizomlarda bulunan oz ve holozitlerin miktar tayini, hidrolizden önce ve hidrolizden sonra olmak üzere değişik yöntemlerle yapılmıştır. Invertaz hidrolizi sonucu redüktör oz miktarındaki artış, sakarozdan ileri gelmektedir. Emülsin ile hidrolizden sonra iyodometrik (12) olarak yapilan tayinde, serbest glukoz ve sakarozun parçalanması ile açığa çıkan glukoza ilâveten, \% 0.09 kadar daha glukoz bulunmuştur. Asit hidroliz uygulandığında, heterozitin de parçalandığı ve arabinozun ayrıldığı anlaşılmaktadır. Sayısal bulgular Tablo II de verilmiştir. 


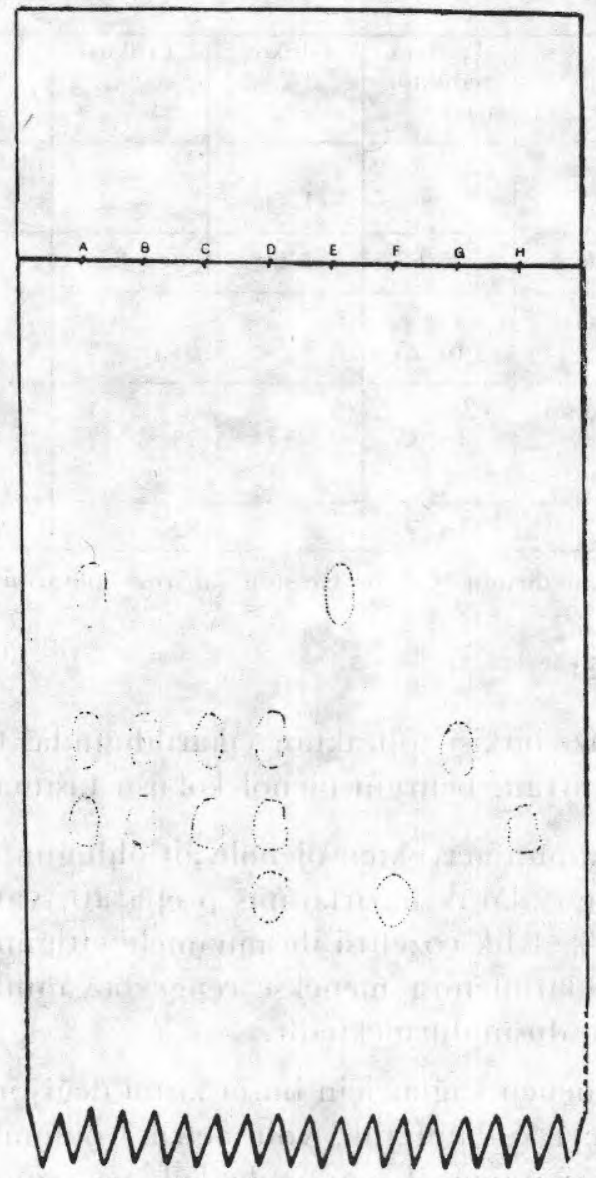

Krom. 1. Oz ve holozitlerin kâğıt kromatografisi ılle ayrılması.

A) ana çözelti, B) Invertaz ile hidrolizden sonra, C) emülsin ile hidrolizden sonra, D) asit ile hidrolizden sonra, E) sakaroz, F) arabinoz, G) glukoz, H) fruktoz.

Kâğıt : Schl. Schüll 2043a $(18 \times 56 \mathrm{~cm})$

Solvan sistemi : $\quad$-butanol: piridin:su $(9: 5: 4)$

Developman süresi : 24 saat

Oda sicaklı̆̆ı : $26^{\circ} \mathrm{C}$

Revelatör : $\beta$-naftilamin/etanol 
Tablo II. Kök ve rizomlarda bulunan oz ve holozit miktarları

\begin{tabular}{|c|c|c|c|c|c|c|}
\hline \multirow{3}{*}{  } & & $\begin{array}{l}\text { Toplam } \\
\text { redüktör } \\
\text { oz (\%) }\end{array}$ & $\begin{array}{c}\text { Glukoz } \\
(\%)\end{array}$ & $\begin{array}{c}\text { Fruktoz } \\
(\%)\end{array}$ & $\begin{array}{c}\text { Sakaroz } \\
(\%)\end{array}$ & $\begin{array}{c}\text { Arabinoz } \\
(\%)\end{array}$ \\
\hline & $\begin{array}{l}\text { Iyodometrik } \\
\text { titrasyon }\end{array}$ & & 1.80 & & & \\
\hline & Bertrand yöntemi & 5.63 & 1.80 & 3.83 & & \\
\hline ప్ & $\begin{array}{l}\text { Invertaz ile } \\
\text { hidroliz }\end{array}$ & 16.25 & \multicolumn{2}{|c|}{5.63} & 10.09 & \\
\hline 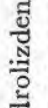 & $\begin{array}{l}\text { Invertazdan sonra } \\
\text { emülsin ile } \\
\text { hidroliz }\end{array}$ & 16.35 & \multicolumn{2}{|c|}{5.73} & 10.09 & \\
\hline 诖 & Asit hidroliz & 16.56 & \multicolumn{2}{|c|}{5.82} & 10.09 & 0.11 \\
\hline
\end{tabular}

(Invert şeker miktarının 0.95 ile çarpımı sakaroz miktarını vermektedir.)

\section{Uçucu Yağ:}

O. heterocarpus bitkisi topraktan çıkarıldığında, toprakaltı kısımları, kurumakla artan, belirgin öjenol kokusu taşımaktadır.

Belirgin kokunun gerçekten öjenole ait olduğunu saptamak amacıyla, su içine kesi alarak hazırlanmıs preparatı, vanilinin \% 70 lik sülfürik asitteki \% 1 lik çözeltisi ile muamele ettiğimiz zaman kabuk ve öz bölgesinin kırmızımsı-menekşe renge boyanması, uçucu yağın öjenol içerdiğini düşündürmektedir.

Sudan ağır uçucu yağlar için büret kısmı değiştirilmiş olan CLEVENGER apareyi kullanllarak, volümetrik yöntemle ve T.K. inde kayıtlı bulunan gravimetrik yöntemle kök ve rizomlarda saptanan uçucu yağ miktarları Tablo III de verilmiştir.

Tablo III. O. heterocarpus kök ve rizomlarındaki uçucu yağ miktarları

\begin{tabular}{|c|c|c|}
\hline Materyal & $\begin{array}{c}\text { Volümetrik } \\
\%(\mathrm{~h} / \mathrm{a})\end{array}$ & $\begin{array}{c}\text { Gravimetrik } \\
\%(\mathrm{a} / \mathrm{a})\end{array}$ \\
\hline $\begin{array}{c}\text { Ciçcekli iken toplanan } \\
\text { Meyvalı" }\end{array}$ & 0.90 & 0.62 \\
0.50 & 0.37 \\
\hline
\end{tabular}

Subuharı distilasyonu ile köklerden elde edilen ve susuz sodyum sülfat üzerinde kurutulan uçucu yağ, sarı renkli olup, kuvvetli öjenol kokusunda, baharlı ve yakıcı lezzettedir. Metil oranj ve fenol ftaleine 
karşı asit reaksiyon gösterir. Uçucu yağın saptanan fiziksel ve kimyasal özelikleri Tablo IV de verilmiştir.

Tablo IV. O.heterocarpus uçucu yağının fiziksel ve kimyasal özelikleri

Spesifik ağırlık, $20^{\circ} \mathrm{G} \quad: \quad 1.0610$

Optik çevirme $\quad:-1^{\circ} .25$

Kirılma indeksi, $20^{\circ} \mathrm{C} \quad: 1.5300$

Etanolde çözünürlük : $1 \mathrm{kısım} \mathrm{uçucu} \mathrm{yağ,} 2 \mathrm{kısım} 70^{\circ} \mathrm{G}$ lik etanolde berrak olarak çözünür.

Asitlik indeksi $\quad: \quad 4.37$

Sabunlaşma indeksi : 5.82

Ester indeksi : 1.45

Asetil indeksi $\quad: 116.30$

Ince tabaka kromatografisi yardımıla uçucu yağın bileşiminde öjenol, nerol ve borneolün bulunduğu saptanmıştır (Krom 2).

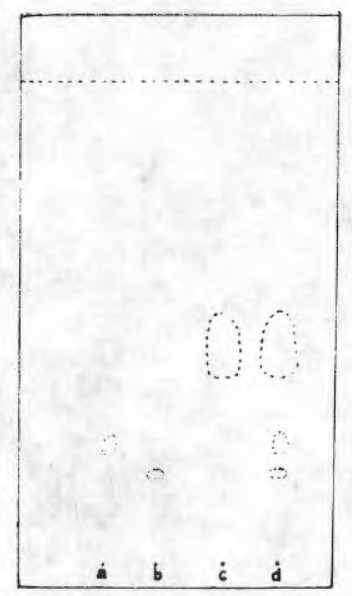

Krom. 2. O. heterocarpus uçucu yağının ince tabaka kromatografisindeki kromatogramı.

a) nerol, b) borneol, c) öjenol, d) uçucu yağ

Adsorban

Solvan sistemi

Developman süresi

Oda sıcaklığı

Revelatör
: Kieselgel G Merck

: benzen : etil asetat $(50: 1)$

: 20 dakika

: $25^{\circ} \mathrm{C}$

: vanilin-sülfürik asit çözeltisi

Uçucu yağın yapısının daha hassas biçimde aydınlatılması için gaz-sıvı kromatografisi kullanılmıştır. Uçucu yağın, n-pentan için- 
deki çözeltisinden $1 \mu \mathrm{l}$, Sistem I'e enjekte etmek suretiyle yapılan analizinde, öjenole ait ve bağıl tutuş zamanı 11.5 olan bir pik elde edilmiştir (Krom. 3).

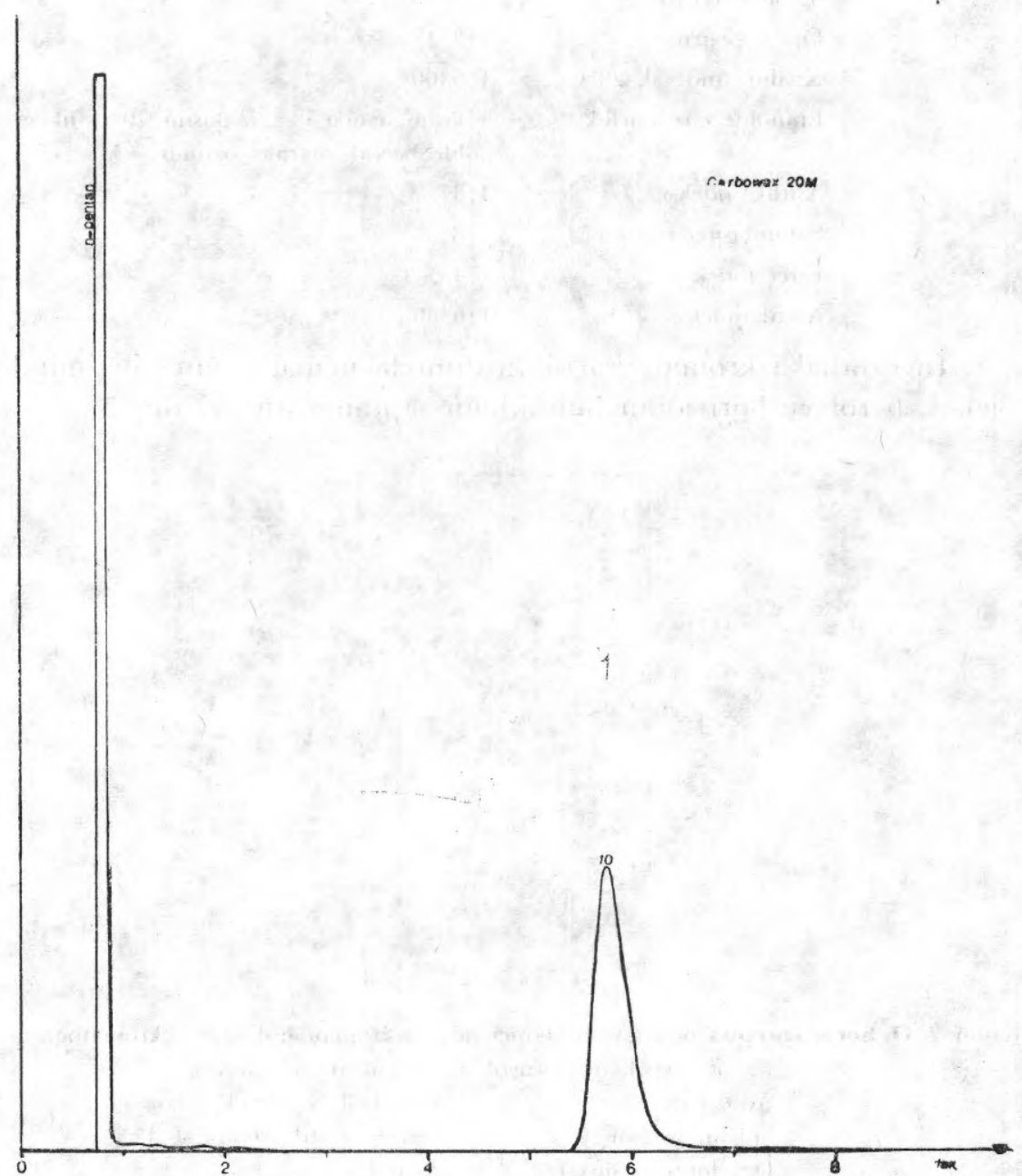

Krom. 3. O. heterocarpus uçucu yağının Carbowax 20M kolonundaki gaz kromatogramı.

Uçucu yağın Sistem $V$ te, yapılan analizi ile yağın büyük bir kısmını öjenol (no. 10)'un oluşturduğu ve az miktarda da nerol (no.9), 
borneol (no. 8), $\alpha$-terpineol (no. 7) gibi diğer terpenik maddelerin bulunduğu görülmüştür (Krom. 4).

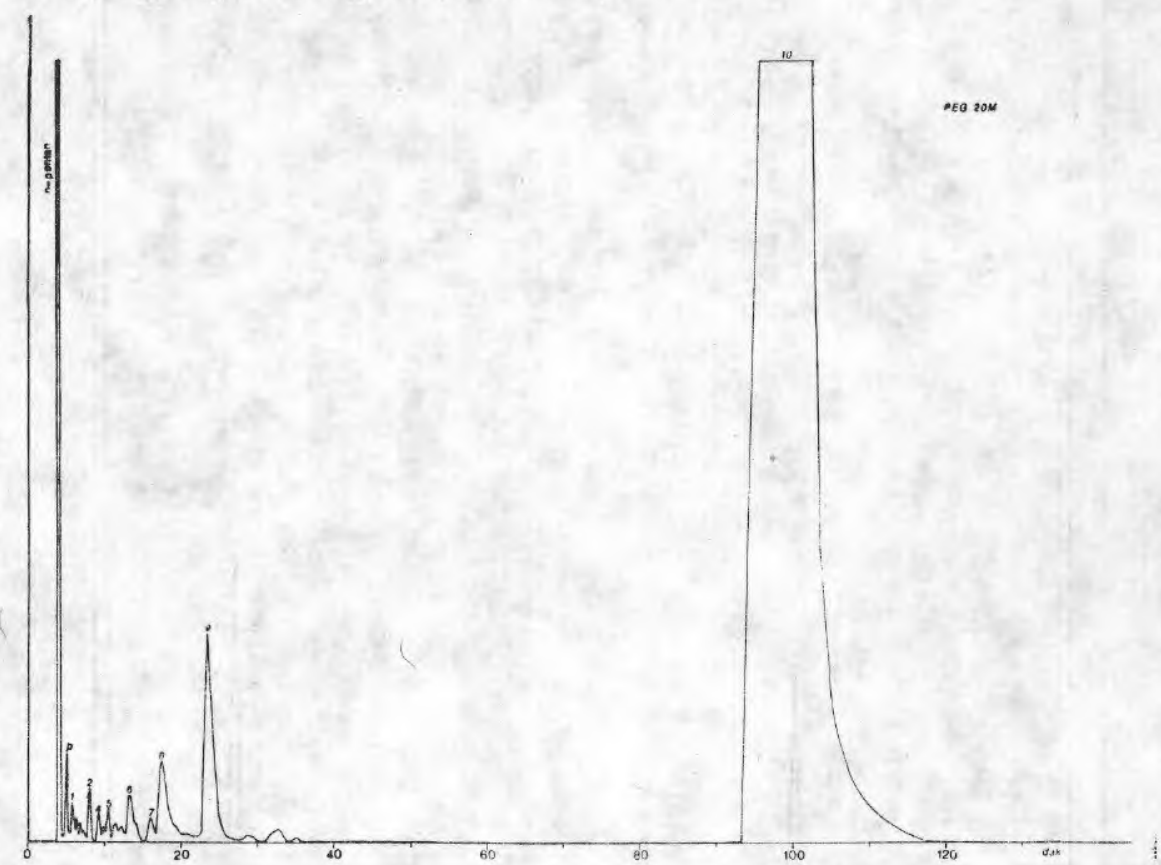

Krom. 4. O.heterocarpus uçucu yağının PEG $20 \mathrm{M}\left(160^{\circ} \mathrm{C}\right)$ kolonundaki gaz kromatogrami.

Monoterpenik hidrokarbürlerin tanınması:

Silikajel sütununda uçucu yağdan n-pentan ile elüe edilen monoterpenik hidrokarbürlerde, pentanın dikkatlice uçurulmasından sonra Sistem III ve IV te yapilan analizler sonucunda bir madde (bağll tutuş zamanı Sistem III de 6.9 ve Sistem IV te ise 5.9) bulunmuş ve tanık maddelerle bunun $\beta$-pinen olduğu saptanmıştır (Krom. 5,6). Bulunan bağıl tutuş zamanları, literatürde (10) verilen değerlere- tamamen uymaktadir.

Oksijenli bileşiklerin tanınması:

Silikajel kolonunda etil asetat ile ayrılan uçucu yağ fraksiyonu, Sistem II ve $\mathrm{V}$ te incelendiğinde 10 tane oksijenli bileşik saptanmıştır. Bunlar ökaliptol, fenkon, tuyon, sitronellal, linalol, kâfur, $\alpha$-terpineol, borneol, nerol ve öjenoldür (Krom. 7,8). 


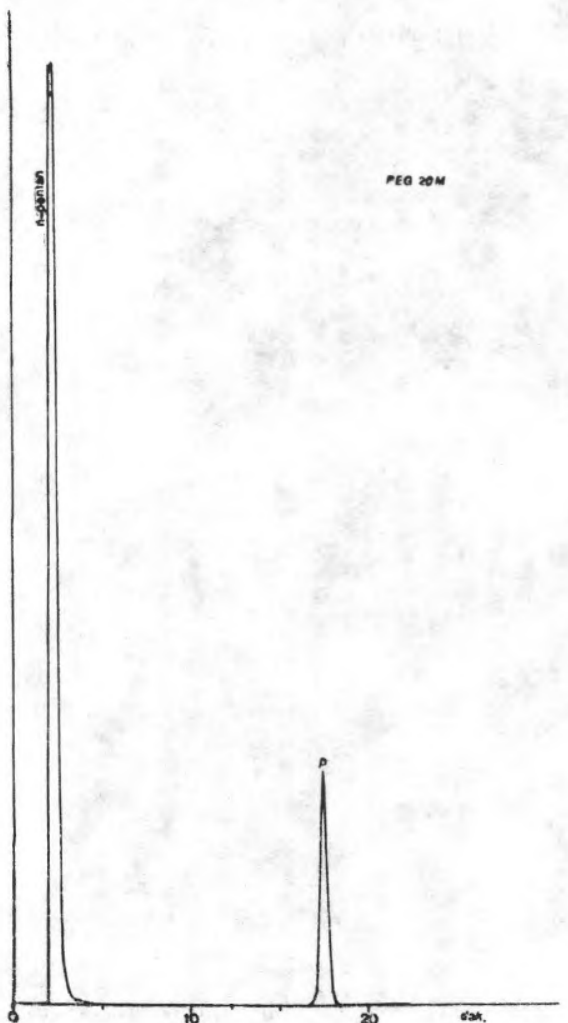

Krom. 5

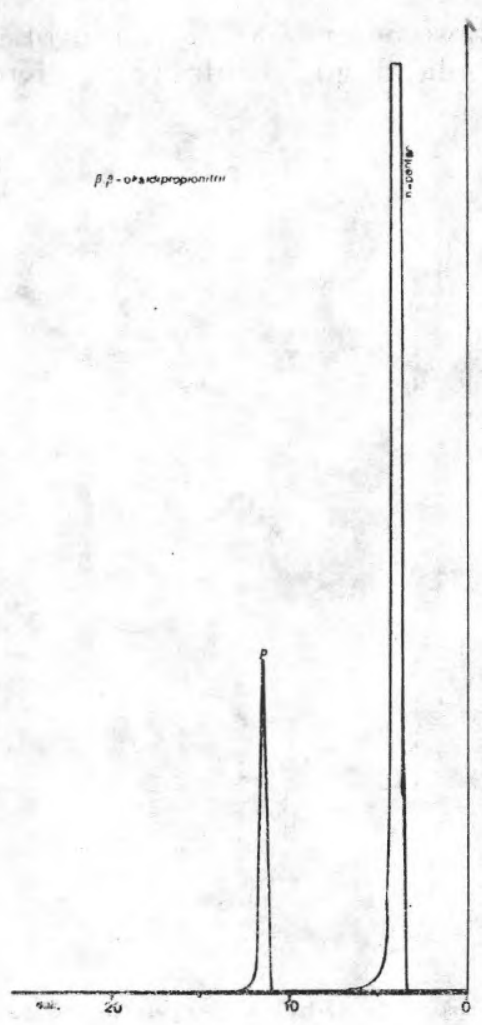

Krom. 6

O. heterocarpus uçucu yağındaki monoterpenik hidrokarbürlerin $60^{\circ} \mathrm{C}$ de PEG $20 \mathrm{M}$ (Krom.5) ve $50^{\circ} \mathrm{Cde} \beta, \beta^{\prime}$-oksidipropionitril (Krom. 6) kolonlarındaki gaz kromatogramları.

Saptanan bu oksijenli bileşiklerin gaz kromatogramlardaki bağıl tutuş zamanları Tablo $\mathrm{V}$ te verilmiştir.

Tablo V. O. heterocarpus'un uçucu yağındaki oksijenli bileşiklerin Sistem III ve V deki bağıl tutuş zamanları

\begin{tabular}{llc} 
Oksijenli bileşikler & Sistem III & Sistem IV \\
\hline ( 1) Ökaliptol & 2.7 & 1.2 \\
( 2) Fenkon & 4.3 & 1.6 \\
(3) Tuyon & $5.4,5.7$ & - \\
( 4) Sitronellal & 6.2 & 1.9 \\
( 5) Linalol & 6.5 & 2.2 \\
( 6) Kâfur & 8.2 & 2.7 \\
( 7) $\alpha$-Terpineol & 9.3 & 3.2 \\
( 8) Borneol & 9.8 & 3.5 \\
(9) Nerol & 11.8 & 4.7 \\
(10) Ojenol & 23.0 & 19.8
\end{tabular}




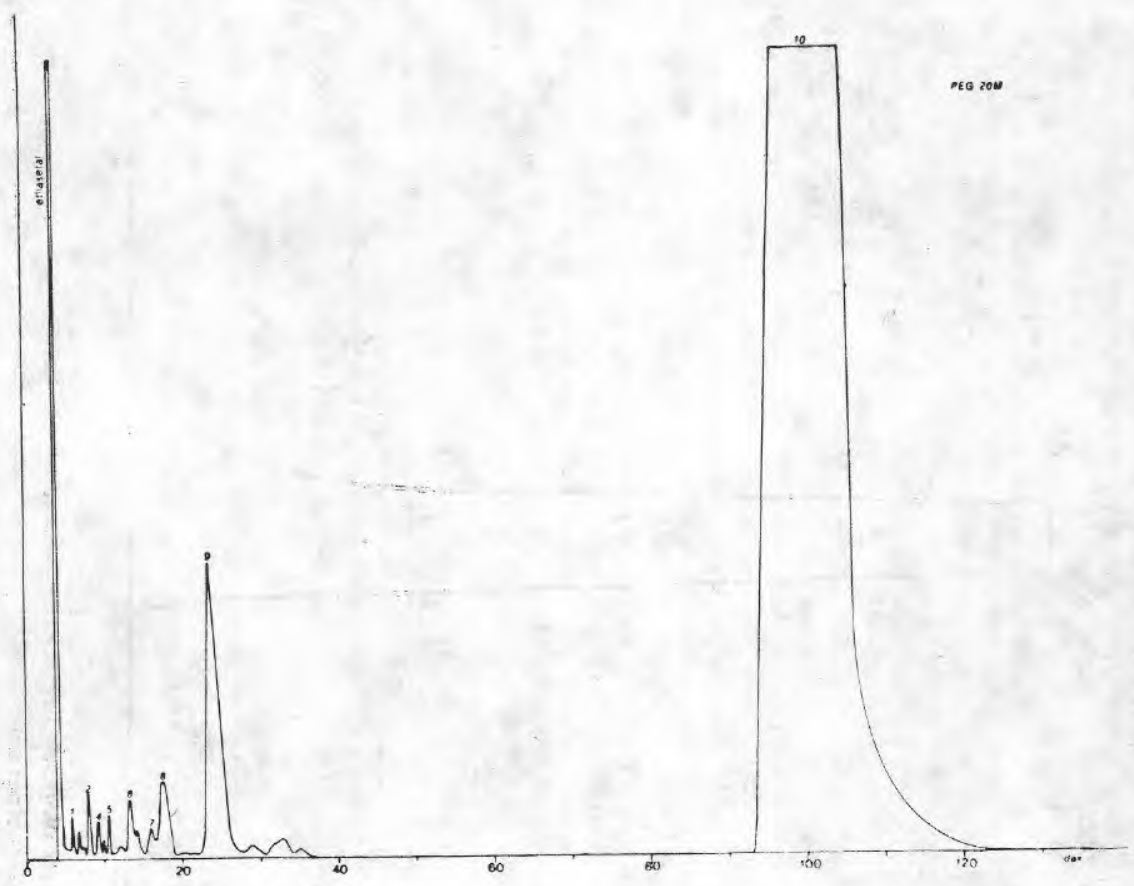

Krom. 7. O. heterocarpus uçucu yağındaki oksijenli bileşiklerin PEG $20 \mathrm{M}\left(160^{\circ} \mathrm{C}\right)$ kolonundaki gaz kromatogrami.

Uçucu yağın büyük kısmını oluşturan öjenolün miktar tayini için üç yöntem uygulanmış ve şu sonuçlar alınmıştır:

Alkali ile oda sıcaklığında ve subanyosunda yapılan tüketmeler sonucu, öjenol miktarı \% 90 ,

Bromür-bromat yöntemi ile yapılan analize göre $\% 83$,

VAN URK yöntemiyle ise \% 84.45 bulunmuştur.

Uçucu yağın bileşiminde bulunan başlıca maddelerin miktarı, gaz kromatogramlarından yararlanarak ta tayin edilmiştir. Her maddeye ait pik alanını Planimetre ile ölçmek suretiyle uçucu yağda $\% 87.17$ öjenol, \% 3.99 nerol ve \% 2.19 borneol bulunduğu saptanmistır.

O.heterocarpus'un toprakaltı kısımlarında bulunan uçucu yağın öjenol bakımından zengin olduğu, şimdiye kadar yaptığımız çeşitli deneylerle kanıtlanmıştır. Fazla miktarda bulunan öjenol, uçucu yağdan izole edilmiş ve aşağıdaki özeliklerinin saptanması ile saf olduğu anlaşılmıştır. 


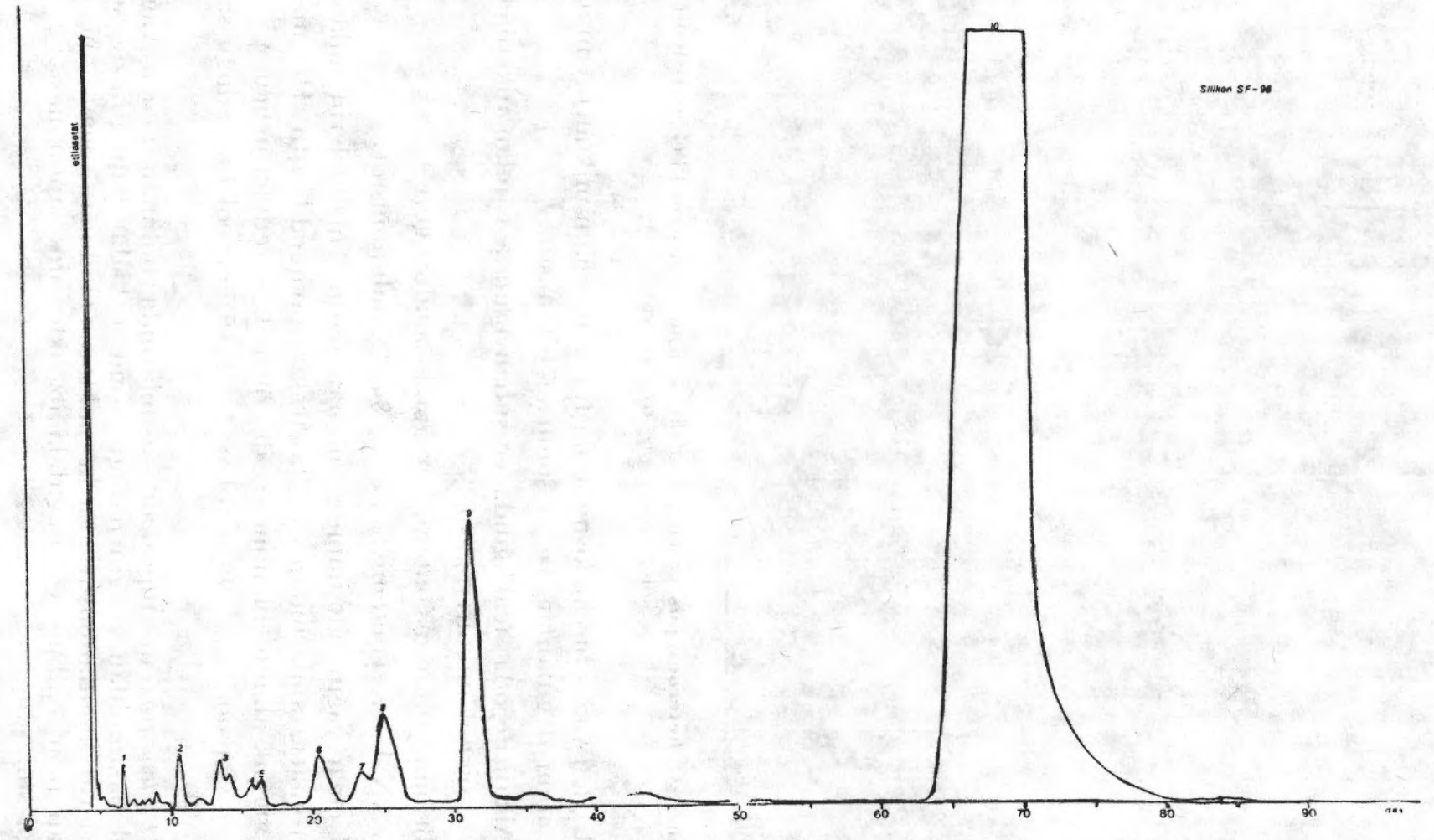

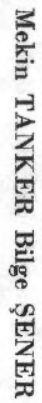

Krom. 8. O. heterocarpus uçucu yağındaki oksijenli bileşiklerin Silicon SF-96 kolonundaki gaz kromatogramı. 
Uçucu yağdan izole edilen renksiz ürünün, gaz kromatografisi ile Sistem I ve $\mathrm{V}$ te tek pik verdiği görülmüştür.

Kırılma indeksi $\left(20^{\circ} \mathrm{G}\right)$ ölçüldü: 1.5400

Kaynama noktası $\left(760 \mathrm{~mm}\right.$ de) saptandı: $253^{\circ} .9 \mathrm{C}$

Pikrat türevi hazırlandı (1), elde edilen kırmızı renkli, iğnecikler halindeki öjenol pikrat kristalleri $62^{\circ} .1 \mathrm{C}$ erimektedir. Bulunan değerler literatürde verilenlere tamamen uymaktadır $(5,7)$.

UV spektrumu alınd, 211,230 , ve $282 \mathrm{~nm}$ dalga boylarında maksimum absorbsiyon, $225 \mathrm{~nm}$ ve $252 \mathrm{~nm}$ dalga boylarında minimum absorbsiyon görülmektedir. Bu spektrum, standart öjenolün UV spektrumuna büyük bir benzerlik göstermektedir (Spektr. 1) (16).

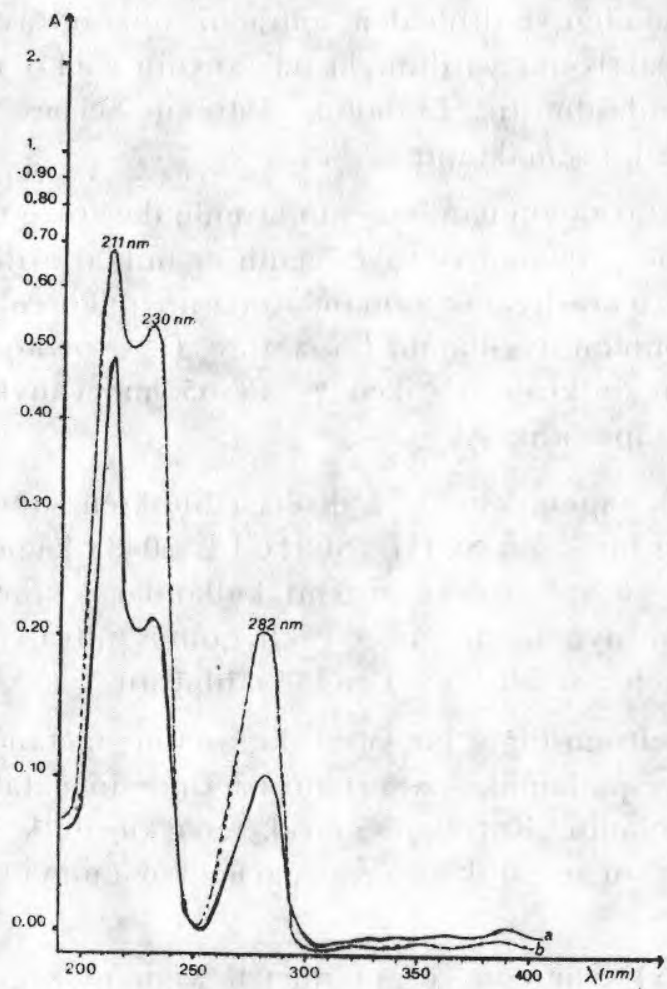

Spektr. 1. Öjenolün UV spektrumu. a) standart öjenol, b) elde edilen öjenol. 
IR spektrumu alındi, spektrumda 2960 ve $2870 \mathrm{~cm}^{-1}$ deki C-H gerilme titreşimlerine ilişkin bantlar, bileşiğin doymamış olduğunu göstermektedir. $1650,1620,1525$ ve $1445 \mathrm{~cm}^{-1}$ deki $\mathrm{C}=\mathrm{C}$ gerilme titreşimleri aromatik yapıyı, 830 ve $805 \mathrm{~cm}^{-1}$ de görülen $\mathrm{C}-\mathrm{H}$ deformasyon bantları 1,2,4 trisübstitüe benzeni, $925 \mathrm{~cm}^{-1}$ deki C-H deformasyon bandı vinil grubunu ve $3580 \mathrm{~cm}^{-1}$ deki-OH gerilme titreşimine ilişkin bant ise, serbest hidroksil grubunu kantlamaktadir. 1150,1139 ve $1045 \mathrm{~cm}^{-1}$ deki bantlar metoksil grubundan, $1280 \mathrm{ve} 1245 \mathrm{~cm}^{-1}$ deki bantlar ise $-\mathrm{OH}$ deformasyonundan dolayı oluşmaktadır (Spektr. 2). Bu spektrum, standart öjenolün IR spektrumu ile tamamen aynıdır (3).

\section{Tanen:}

Kök ve rizomlardan hazırlanan etanollü ekstrede tanenin varlığı, farmakopelere göre saptanmıştır. Stiasny reaksifi ile kateşik tanenin bulunmadığ yum siyanür reaksiyonu yardımiyla da tanenin gallotan en yap1sında olduğu anlaşılmıştır. Etanollü ekstre ne serbest ne de bağlı olarak elajik asit taşımaktadır.

Tanen miktar tayini için, tanenin kromlu deri tozu tarafindan tutulması özeliğine dayanan ve tüketmenin az miktarlardaki çözeltiyle, fakat çok defa tekrarlıyarak tamamlanmasını öngören, değiştirilmiş "Deri tozu" yöntemi uygulandı. Buna göre, $O$. heterocarpus'un toprakaltı kısımlarının, bitki çiçekli iken \% 18.65 , meyvalıyken \% 13.11 tanen içerdiği saptand.

Elde edilen tanen, asit ile hidroliz edildikten sonra nötralleştirilmiş çözeltinin bir kısmı SGHL. SGHÜLL 2043a kâğıdı ve n-butanol: piridin:su $(6: 4: 3)$ solvan sistemi kullanılarak inen usul kâğıt kromatografisine uygulandı. Amonyaklı gümüş nitrat revelatörü ile glukoza karşı gelen siyah bir leke elde edilmiştir.

Nötral çözeltinin diğer bir kısmı da, aseton: metanol: su $(5: 4: 1)$ solvan sistemi ve poliamid ${ }_{11}$ adsorbanı üzerinde ince tabaka kromatografisine uygulandi. Revelatör olarak ferri klorür kullanıldığında, Rf değeri 0.67 olan ve gallik asite karşı gelen koyu mavi bir leke görülmektedir.

BERTRAND yöntemi ve gravimetrik yöntem uygulanarak gallotanenin hidroliz ürününde, oz ve gallik asit miktar tayini yapil- 
Spektr.2. Öjenolün IR spektrumu. 
dığında bulunan \% 51.00 glukoz ve $\% 48.80$ gallik asit, gallotanenin bir bir molekül gallik asit ve bir molekül glukozdan oluştuğunu göstermiştir.

Ayrıca bitkinin toprakaltı kısımlarında bulunan serbest gallik asit metanolle tüketilerek (9), \% 1.25 oranında elde edilmiştir. Elde edilen gallik asidin erime noktası $\left(231 .{ }^{\circ} 6 \mathrm{C}\right)$, UV (218 ve $272 \mathrm{~nm}$ dalga boylarında maksimum absorbsiyon) ve IR spektrumları saf gallik asidinkine tamamen uymaktadır.

\section{TARTIŞMA ve SONUĢ}

Bulgularımıza göre, O. heterocarpus bitkisinin toprakaltı kısımları, bitki çiçekli iken $\% 0.9$, meyve oluştuğu zaman $\% 0.5$ oranında karanfil kokulu bir uçucu yağ taşımaktadır. Uçucu yağın büyük bir kısmını ( $\%$ 87.17) öjenol, geriye kalanını da terpenlerin oksijenli türevleri oluştururken hidrokarbür olarak, sadece ve $\% 0.69$ oranında $\beta$-pinen bulunmaktadır.

Eskiden Avrupa'da drog olarak kullanılmış olan ve memleketimizde de bulunan $G$. urbanum'un toprakaltı kısımlar $\% 0.3$ oranında uçucu yağ taşımaktadır. Bu yağın \% 68.80 nini öjenol, \% 7.20 sini kâfur oluşturur ve az miktarda da diğer terpen alkolleri bulunur (Krom. 9).

O. heterocarpus uçucu yağının fiziksel özelikleri ve bileşimi yönünden $G$. urbanum uçucu yağı ve öjenolünden dolayı kullanılan Eugenia caryophyllata uçucu yağı ile karşılaştırılması Tablo VI da verilmiştir. Tablo incelendiğinde, O.heterocarpus ile G.urbanum'un uçucu yağlarındaki maddelerin hemen hemen aynı fakat miktar bakımından farklı olduğu açıkca görülmektedir.

Diğer taraftan O.heterocarpus uçucu yağı fiziksel özelikleri ve öjenol miktarı yönünden de literatürde (6) karanfil yağı için verilen değerlere tamamen uymaktadır. $\mathrm{Bu}$ üç kaynaktan O.heterocarpus uçucu yağının, öjenol yönünden diğer ikisine oranla daha zengin olduğu gaz kromatogramlarında da belirgin olarak görülmektedir (Krom. 4, 9, 10).

O.heterocarpus ve E.caryophyllata uçucu yağlarının IR spektrumlarını da incelemek suretiyle bileşimlerinde bulunan maddeler 
Orthurus Heterocarpus (Boiss.) Juz. Bitkisinin Kökleri...

Tablo VI. O. heterocarpus uçucu yağının G.urbanum uçucu yağı ve Karanfil yağı ile karşılaştırılması

\begin{tabular}{|c|c|c|c|}
\hline$\overline{x+7 n}$ & $\begin{array}{l}\text { O. heterocarpus } \\
\text { uçucu yağı }\end{array}$ & $\begin{array}{l}\text { G. urbanum } \\
\text { uçucu yağı }\end{array}$ & Karanfil yağ1 \\
\hline $\begin{array}{l}\text { Spesifik ağırlık } \\
\text { Kirlma indeksi } \\
\text { Optik çevirme }\end{array}$ & $\begin{array}{c}1.0610 \\
1.5300 \\
-1^{\circ} .25\end{array}$ & $\begin{array}{l}1.0410^{*} \\
1.4250^{*} \\
+10^{\circ *}\end{array}$ & $\begin{array}{c}1.038-1.060^{*} \\
1.527-1.535^{*} \\
-1^{\circ} .30^{*}\end{array}$ \\
\hline $\begin{array}{l}\text { ß- Pinen } \\
\text { Ökaliptol } \\
\text { Fenkon } \\
\text { Tuyon } \\
\text { Sitronellal } \\
\text { Linalol } \\
\text { Kâfur } \\
\alpha-\text { Terpineol } \\
\text { Borneol } \\
\text { Nerol } \\
\text { Öjenol } \\
\text { Safrol } \\
\text { Benzil alkol }\end{array}$ & $\begin{array}{r}0.69 \\
0.39 \\
0.61 \\
0.89 \\
0.41 \\
0.49 \\
1.19 \\
0.59 \\
2.19 \\
3.99 \\
87.17 \\
- \\
-\end{array}$ & $\begin{array}{c}4.61 \\
0.35 \\
0.80 \\
- \\
- \\
0.47 \\
7.20 \\
2.00 \\
3.10 \\
3.20 \\
68.80 \\
2.30 \\
-\end{array}$ &  \\
\hline
\end{tabular}

* Literatürde verilen değerlerdir.

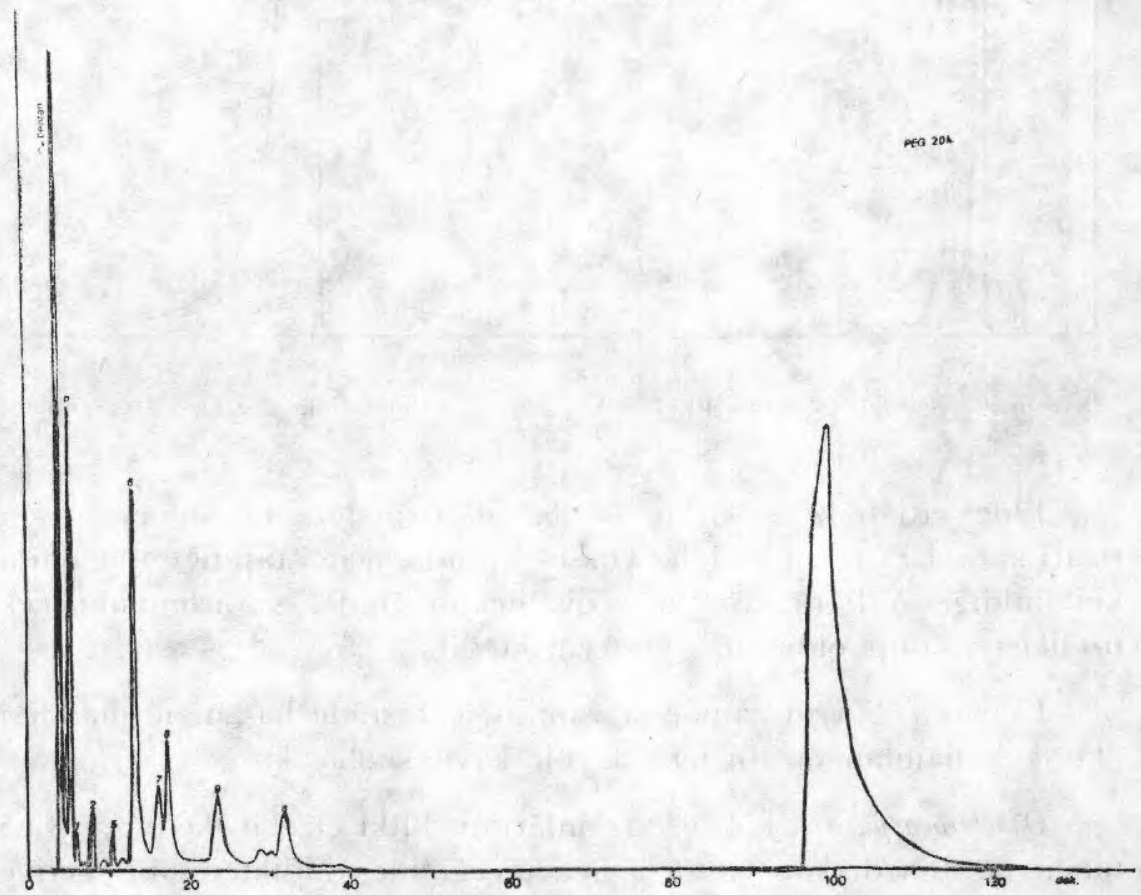

Krom. 9. G. urbanum uçucu yağının PEG $20 \mathrm{M}\left(160^{\circ} \mathrm{C}\right)$ kolonundaki gaz kromatogramı. 
yönünden bir karşılaştırma yapılabilir (Spektr. 3,4). Her iki spektrumda $3580,1150,1139,1045$ ve $925 \mathrm{~cm}^{-1}$ de görülen bantlar, karakteristik öjenol bantlarıdır.

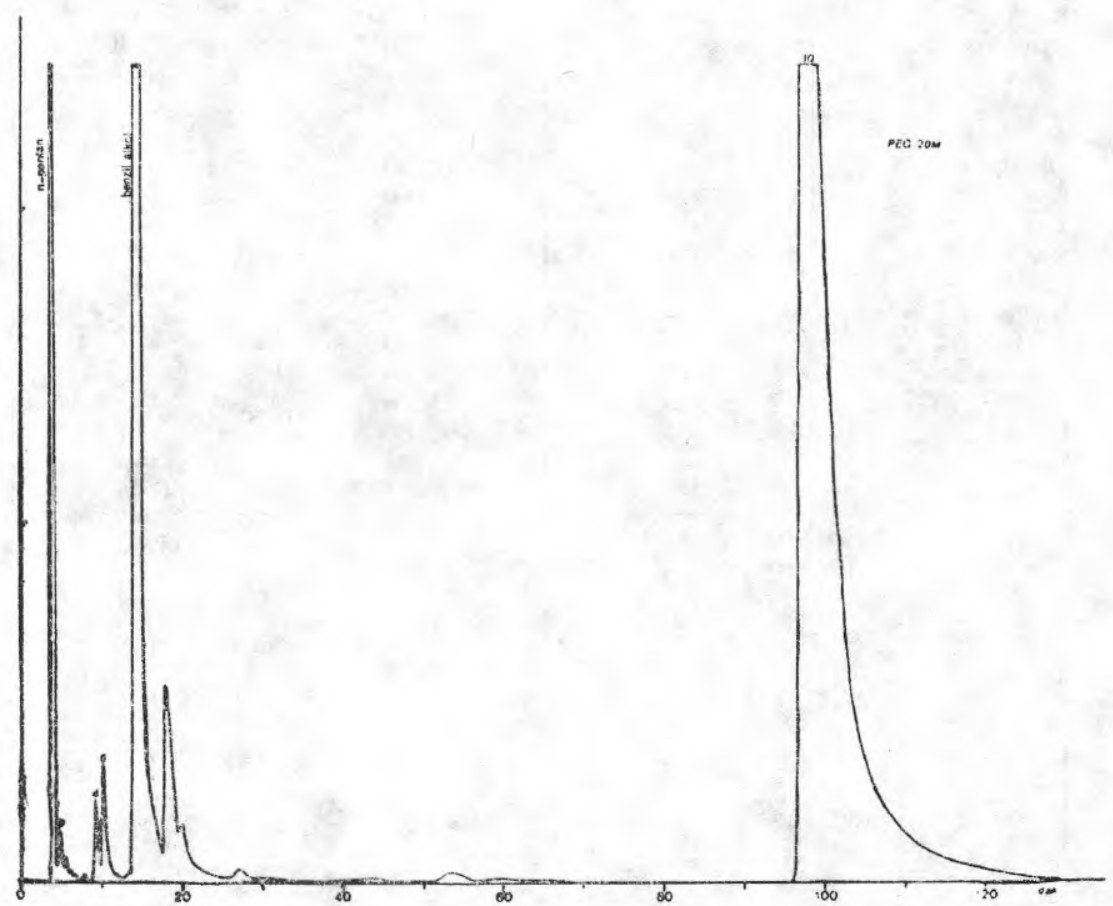

Krom.10. Karanfil yağının PEG $20 \mathrm{M}\left(160^{\circ} \mathrm{C}\right)$ kolonundaki gaz kromatogram.

Elde ettiğimiz sonuçlar ve'karşlaştırmalar, bu uçucu yağın ticari karanfil yağından daha yüksek oranda öjenol taşıdığını ve onun kullanıldığı yerlerde, özellikle diş hekimliğinde, yararlanılabilecek özeliklere sahip olduğunu göstermektedir.

Uçucu yağ aynı zamanda vanilin sentezinde başlangıç maddesi olarak kullanılan öjenol için de bir kaynak olacaktır.

O.heterocarpus'un kök ve rizomlarının bitki çiçekli iken \% 18.65 tanen taşıdığı dikkate alınırsa, uçucu yağ elde edildikten sonra geriye kalan materyalden, tanen elde edilişinde yararlanılabilir. Ayrıca bu tanenden gallik asit de izole edilmektedir ki, bu asit hem antioksidan 


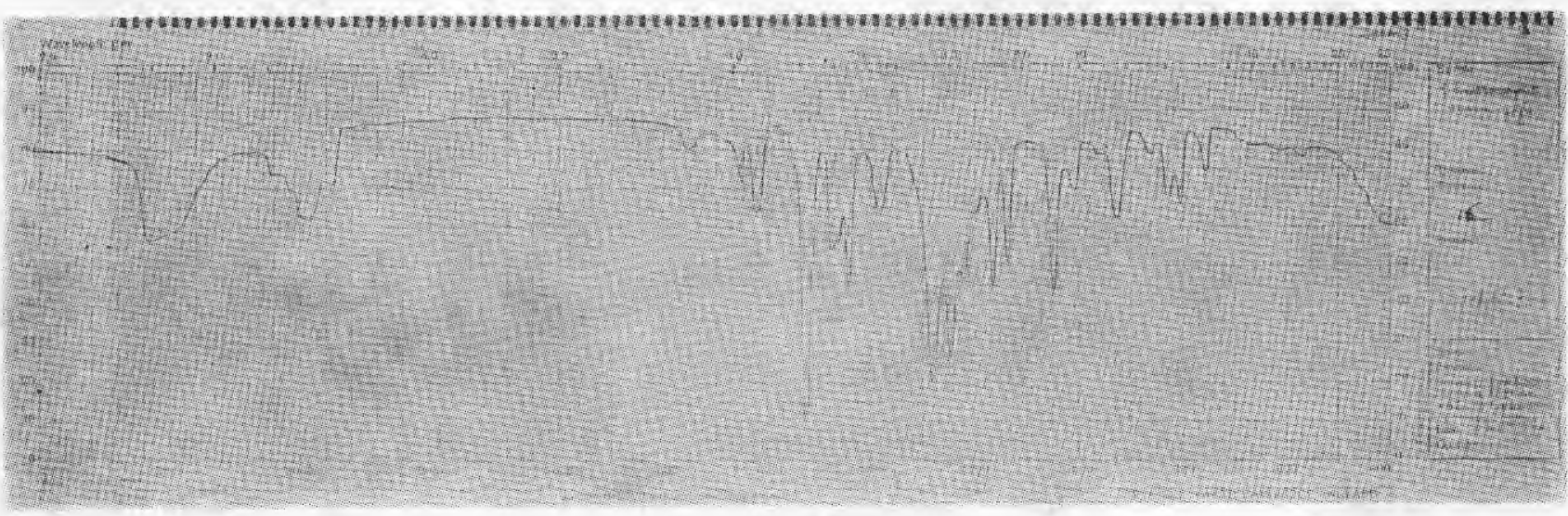

Spektr. 3. O. heterocarpus uçucu yağınin. IR spektrumu. 


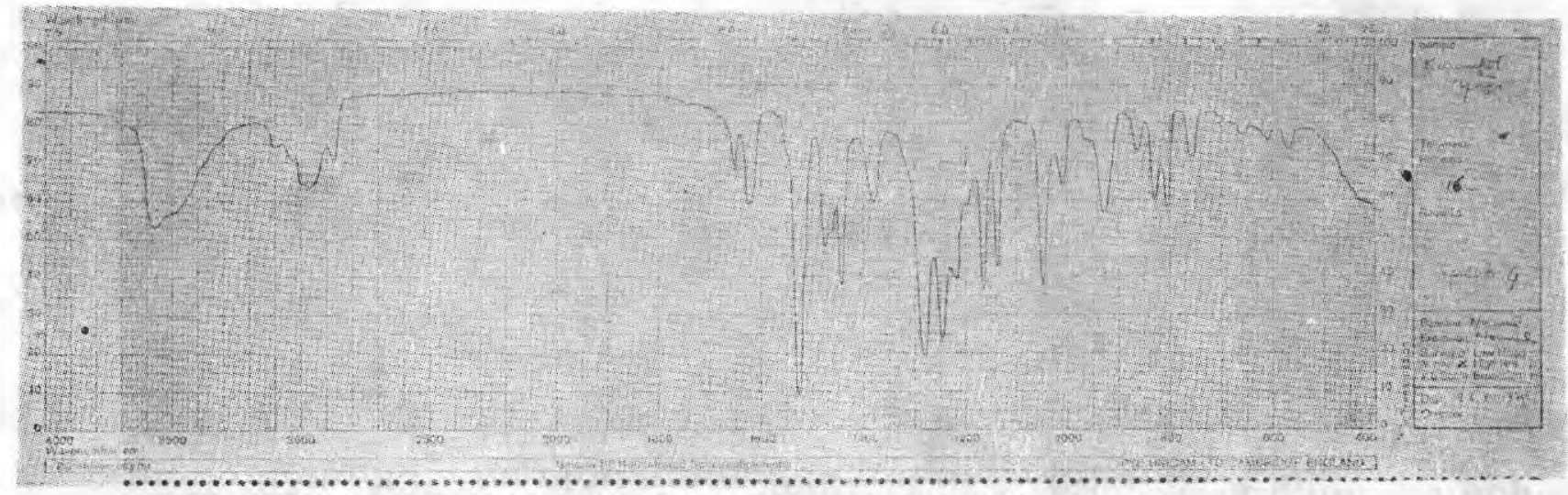

总

Spektr. 4. Karanfil yağının IR spektrumu. 
özelikte bir madde olduğundan propil gallat halinde besinlere, yağlara, emülsiyonlara katılmakta, hem de bizmut subgallat halinde deri hastalıklarında, kurutucu etkisinden dolayı kullanılmaktadır.

\section{Ö Z E T}

Bu çalışmada, güney Anadoluda yaygın olarak bulunan ve halk arasında "karanfil, karanfil kökü", gibi isimlerle tanınan Orthurus heterocarpus (Boiss.) Juz., bitkisinin toprakaltı kısimlarinda bulunan uçucu yağın bileşimi, gaz kromatografisi yardımıyla ortaya konulmuştur.

O.heterocarpus'un çiçekli ve meyvalı iken toplanıp, kurutulmuş toprakaltı kısımlarından subuharı distilasyonu ile sırasıyla $\% 0.9$ ve $\% 0.5$ oranında sarı renkli, yakıcı lezzetli ve karanfil kokulu bir uçucu yağ elde edilmiştir. Uçucu yağda \% 87.2 öjenol bulunmuştur.

Öjenol, alkali ekstraksiyon ve kolon kromatografisi yardımıyla yağdan izole edilerek K.N., kırılma indeksi, IR ve UV spektrumları ve pikrat türevinin hazırlanması ile tanınmıştır.

Ayrıca köklerden tanen ve bundan da gallik asit elde edilmiştir. Elde edilen gallik asidin E.N., UV ve IR spektrumları ile saf olduğu anlaşılmıştır.

Uçucu yağ ve tanene ek olarak bitkinin toprakaltı kısımlarında $\% 1.80$ glukoz, $\% 3.83$ fruktoz, $\% 10.09$ sakaroz ve $\% 0.11$ arabinoz bulunmaktadır.

\section{S U M M A R Y}

In this research, the composition of the volatile oil of the underground parts of Orthurus heterocarpus (Boiss.) Juz., which is widespread in south part of Anatolia, were investigated by means of gasliquid chromatography. This plant is known as "clove or root of clove" local people.

The volatile oil is obtained by steam distillation from the air dried underground parts of $O$. heterocarpus which were collected either flowering or fruiting stage. The yields of volatile oil are $0.9 \%$ and $0.5 \%$ respectively. This oil has a yellow colour, pungent taste and clove-like odour. Volatile oil contains $87.2 \%$ of eugenol. 
Eugenol is the main constituent of this oil which was isolated by using alcali extraction and the column chromatography and identified by means of boiling point, refractive index, IR, UV spectrums and also by preparing picrate derivative.

The tannin was obtained from the roots and gallic acid was isolated from the tannin. Gallic acid was identified with melting point, UV and IR spectrums.

The presence of sugars and their percentages were indicated. Glucose $(1.80 \%)$, fructose $(3.83 \%)$, saccharose $(10.09 \%)$, arabinose $(0.11 \%)$ were found within the underground parts of O.heterocarpus.

As a result of our studies, we concluded that O.heterocarpus may serve as a source of volatile oil rich in eugenol and it can be used to obtain tannin.

\section{I T E R A T Ü R}

1. Baril, O.L., Megrdichian, G.A., F. Amer. Chem. Soc. 58, 1415 (1936).

2. Bedoukin, P.Z.- Perfumery and Flavoring Synthetics, Second Edition, Elsevier Publishing Gompany, Amsterdam (1967).

3. Bellanato, J., Hidalgo, A. - Infrared Analysis of Essential Oils, Heyden and Son Ltd., London (1971).

4. Gildemeister, E., Hoffmann, Fr.,- Die Ätherischen Öle, Band II, 4. Auflage, Akademie-Verlag, Berlin (1959).

5. Ibid. Band III d, (1966).

6. Guenther, E.- The Essential Oils, Volume IV, D.Van Nostrand Company, Inc. New York (1950).

7. Karrer, W.- Konstitution und Vorkommen der organischen Phlanzenstoffe, Birkhaeuser Verlag, Basel (1958).

8. Krupińska, A., Ann. Pharm. (Poznan), 8, 93 (1970).

9. Martino, V.S., Graziano, M.N., Hnatyszyn, O., Coussio, J.D., Planta Med. 27 (3), 226 (1975).

19. Scheffer, J.C., Baerheim Svendsen, A., J. Chromatog. 115, 607 (1975).

11. Scott, W.- Standart Methods of Chemical Analysis, $5^{\text {th }}$ ed. Vol. II, D.Van Nostrand Company, New York (1939,.

12. Tanker, M., Istanbul, Ecz. Fak. Mec., 2, 84 (1966).

13. Tanker, N., Demir, E., Ankara, Ecz. Gak. Mec., 2, 89 (1972).

14. Tanker, N., Şener, B., Ankara, Ecz. Fak. Mec., 7, 49, (1977).

15. Van Urk, H.W., Pharm. Weekblad, 62, 667 (1925).

16. Vespe, V.C., Boltz, D.F., Analytical Chem., 24, 664 (1952). 